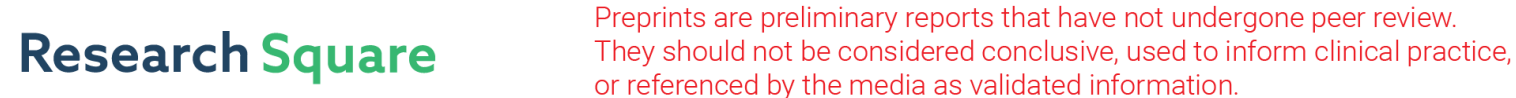 \\ In-Situ X-Ray Tomography on Permeability Evolution of $\mathrm{C} / \mathrm{SiC}$ Porous Ceramic for Hypersonic Vehicles
}

\section{Bo Zhang}

Beijing Jiaotong University

Haiming Huang ( $\nabla$ huanghaiming@tsinghua.org.cn )

Beijing Jiaotong University

Shengchuan Wu

Southwest Jiaotong University

Weijie Li

Beijing Jiaotong University

Jie Huang

Beijing Jiaotong University

Andi Lin

Beijing Jiaotong University

Qian Wu

Beijing Jiaotong University

Yuexun Liu

Southwest Jiaotong University

Tiqiao Xiao

Shanghai Synchrotron Radiation Facility, Shanghai Advanced Research Institute

\section{Research Article}

Keywords: $\mathrm{C} / \mathrm{SiC}$ porous ceramics, permeability mechanism, transpiration cooling, in-situ synchrotron Xray tomography, hypersonic vehicles.

Posted Date: May 26th, 2021

DOl: https://doi.org/10.21203/rs.3.rs-557941/v1

License: (c) (i) This work is licensed under a Creative Commons Attribution 4.0 International License. Read Full License 


\section{Abstract}

Transpiration cooling system in hypersonic vehicles still remains a challenge due to the limitations of observing permeability and microstructure evolution of porous medium filled with coolant. To tackle this problem, a novel compression-permeation device is designed with high-resolution X-ray tomography system, and then an investigation on permeability evolution mechanism of a $\mathrm{C} / \mathrm{SiC}$ porous ceramic under pressure is performed using in-situ X-ray imaging and the compression-permeation device. The experimental results indicate that the pore-space fluid flow is displayed in terms of three-dimensional streamlines, making the permeability mechanism clear. Meanwhile the porosity along the thickness of ceramic under pressure has been obtained by synchrotron tomography testing, and it is also verified that the porosity of $\mathrm{C} / \mathrm{SiC}$ ceramic fabricated in our research group is basically uniform (>95.4\%) along the thickness. Furthermore, we have found the evolution rule for permeability of porous ceramic with water, which depends on the variation of its microstructure under different loads.

\section{Introduction}

Transpiration cooling is regarded as the most potential thermal protection system in future hypersonic cruise vehicles (see Fig. 1) for its superior properties such as reusability and maintaining the aerodynamic shape of the advanced vehicles ${ }^{[1,2]}$. Porous medium is usually used as a counter flow heat exchanger and channels for coolant, which shows an essential effect on the cooling performance of vehicle surfaces ${ }^{[3-5]}$. Whereas this cooling system is hardly utilized due to the low reliability of porous medium. For examples, the porosity of cross sections along the thickness of porous ceramic cannot be measured accurately, and this internal characteristics due to complex microstructures shows a crucial influence on the transpiration cooling performance ${ }^{[6,7]}$. Furthermore, during the flight process at super high speed, the porous medium is necessarily subjected to complex loads including the external aerodynamic load, seepage pressure of coolant, heat stress caused by aerodynamic heating, and structural load of the vehicles ${ }^{[8-12]}$. Thus, it is a significant issue whether the flow of coolant can be precisely calibrated and the uniformity of coolant in the porous medium can still remain unchanged or not while the porous medium undergoes heavy loads ${ }^{[13-15]}$. It is urgent to elucidate the permeability evolution subjected to external loads. Unfortunately, none of works have been conducted due to technological cause.

It is worth that the permeability evolution rules during the deformation and failure of rock specimens have been investigated in the geotechnical engineering including drilling for oil and gas ${ }^{[16,17]}$, stability analysis and micro-crack propagation of materials ${ }^{[18,19]}$, and seepage flows in porous media [19-21]. These researches indicate that the rock has a distinct permeability difference during deformation stages [22-24]. The microstructural evolution of the materials with high porosity has been preliminarily discussed [25-27], but the effect of permeability behaviors has not been elucidated. Nevertheless, the methodology used can be referenced to investigate the permeability and microstructural features for porous medium 
(C/SiC porous ceramic in this work can be thought as one type of porous medium) subjected to dynamic loads during transpiration cooling.

In this work, a novel compression-permeation device is firstly designed in order to reveal the mechanism of permeability evolution of porous ceramic. Then, a detailed investigation on the permeability evolution mechanism of $\mathrm{C} / \mathrm{SiC}$ porous ceramic potentially applied into hypersonic vehicles exposed to compression was tentatively carried out by using the third generation high-resolution synchrotron

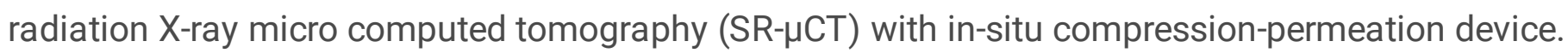

\section{Experimental Procedure \\ $2.1 \mathrm{C} / \mathrm{SiC}$ prous ceramic}

The $\mathrm{C} / \mathrm{SiC}$ porous ceramic sample studied here with the diameter of $4 \mathrm{~mm}$ and the height of $4 \mathrm{~mm}$ was prepared from as-received ceramic raw material using grinding-mould pressing-sintering process ${ }^{[28,29]}$. In detail, the chopped carbon fibers with the diameter of $7 \mu \mathrm{m}$ are firstly added into the prepared SiC ceramic slurry. The dried mixture including carbon fibers and SiC particles (usually with the average diameter of $10 \mu \mathrm{m}$ ) is then grinded into hybrid powders of micron, which are pressed at $100 \mathrm{MPa}$ in the cylindrical mould to form green bodies. The green bodies are further sintered at $1300^{\circ} \mathrm{C}$ in a pure nitrogen flow atmosphere. This final material physically presents low density, high compressive strength, uniform pore distribution, and excellent permeability. Particularly, it has a superior transpiration cooling performance during the oxyacetylene flame test, which usually shows huge potential for the application into advanced hypersonic vehicles. Figure 2 presents fractured features before and after compression tests of $\mathrm{C} / \mathrm{SiC}$ ceramic.

\subsection{In-situ X-ray imaging}

High-resolution BL13W1 is an X-ray imaging beamline at Shanghai Synchrotron Radiation Facility (SSRF, China) with an optimized 3.5 GeV electron storage ring ${ }^{[30-32]}$. It can devote to various scientific fields ${ }^{[33-}$ 37], including advanced material and structural characterization due to its unique advantages of high brightness, high purity and high collimation ${ }^{[38-40]}$ over traditional laboratory X-ray machine. Figure 3 shows the schematics of in-situ testing system compatible with the BL13W1 of the SSRF. It can be illustrated that high energy $\mathrm{X}$-rays emitted from the emitter can penetrate the $\mathrm{C} / \mathrm{SiC}$ porous ceramic sample (totally 6 samples were here used with $4.0 \mathrm{~mm}$ height and $4.0 \mathrm{~mm}$ diameter) installed at an in situ compression-permeation device, and the penetration signal could be accurately captured using the CCD detector (16 bit dynamic, $2048 \times 2048$ pixel array) with a pixel size of $3.25 \mu \mathrm{m}$, which was capable of identifying the mixture.

The compress-permeation machine consists of a miniature loading device, a water pump, an electronic balance, and some auxiliary equipment ${ }^{[41-43]}$. The device is capable of carrying out the permeability test while the sample is subjected to different interrupted loading. Figure 4 gives the compression-permeation 
testing diagram. Stainless steel sinks are often utilized to pass the stress to the porous ceramic sample and are also used as a water inlet and a water outlet, respectively. Filter plates with uniform holes can evenly disperse water on the surface of the porous sample. Silicone tube and sealing tape can avoid the water flow permeate along the outer wall surface of the porous sample. During this compression process, the miniature loading device was set on the sample stage, which would be rotated 180 degrees for getting photos with different angles of the porous sample.

In this compression experiment, the optimized photon energy of X-ray beam was about $25 \mathrm{keV}$, the distance from the ceramic sample to the CCD camera was $18 \mathrm{~cm}$ as shown in Fig. 4b, and an exposure time was selected to be $1 \mathrm{~s}$ or so. This in-situ compression process can be monitored by a user controlling software and then can be initially analyzed as illustrated in Fig. 4b. A total of 720 radiographs were acquired over an angular range of $0-180^{\circ}$ for each SR- $\mu$ CT. For each scanning, we additionally record 5 dark fields and 22 flat field images to correct the raw projections. During the permeability testing, the water pressure difference was $0.08 \mathrm{MPa}$, the gravity of water was neglected.

\section{Results And Discussions}

\subsection{Permeability mechanism}

Totally 747 original images including projections, dark field and flat field images were captured in one cycle. However, they only show side elevation instead of directly reflecting the inner structure of this porous ceramic, as shown in Fig. 5(a). So it needs to transfer the original images to slice images through ReNamer, P3 and P3B software.

These slice images can visually show cross-section views. The cross section $(Z=3.068 \mathrm{~mm})$ of ceramic sample after failure is selected to display the cracks in Fig. 5(b), while the rendered models are chosen from the ceramic sample before loading in Fig. 5(d), (e) and (f). Gray values of pixels in binary images are strictly divided into two gray values for presenting information more distinct. White region represents the matrix of porous ceramic, and black gray value exhibits the pore structures information (Fig. 5(c)). The image processing from slice images to binary images is achieved by Image $\mathrm{J}$ software. The image analysis for the greyscale pixel intensity value of ceramic matrix and pore structure is carried out using this software. There is a marked difference between the greyscale value of the ceramic matrix pixels and the pore structure pixels. Then the threshold has been selected according to the image segmentation [44${ }^{46]}$ in order to transform to black and white ones. Three-dimensional reconstruction of this porous ceramic is achieved through these slice images with Avizo software in this paper. Each voxel represents a physical volume of $\sim 3.25 \times 3.25 \times 3.25 \mu \mathrm{m}^{3}$. Random part of this porous ceramic (diameter of $337.9 \mu \mathrm{m}$, height of $737 \mu \mathrm{m}$ ) has been selected to show the pore structures and permeability process, as shown in Fig. 5(d), (e) and (f). It has a uniform distribution for pores inside the porous ceramic (see Fig. 5(d)). White region represents the matrix and blue region is regarded as pores inside the porous ceramic in $5(d)$. 
Pore characteristics are extracted from three-dimensional model of porous ceramic (see Fig. 5(e)). Figure 5(f) shows the state of permeability test of porous ceramic, and three-dimensional streamlines obtained by using Avizo software are used to simulate the pore fluid flow based on the Darcy's law and the Navier-stokes equation. Streamlines with different colors represent flow rates in this permeability simulation process, it also indicates uniformity of permeability during the permeability test. The red streamlines denote faster flow rate, while blue streamlines show slower flow rate. According to mass conservation of incompressible fluid, the smaller area of flow passing can contribute to a faster flow rate, so the streamlines can visually display the porosity and size of pores. Note that where streamlines are concentrated, pores are also more concentrated, which indicates that these streamlines can also be used to qualitatively and visually identify the pore zones information inside the porous ceramic. As we all know, fluid usually escapes the region with bigger flow resistance, and prefers to flow through the pores structures with smaller flow resistance, this phenomenon may cause heat transfer deterioration in the transpiration cooling. On the basis of streamlines, porosity uniformity of porous ceramic can still be further improved by optimizing the fabrication technology even though the porosity is basically uniform. The streamlines video associated with this permeability process can be found in the supplementary material.

\subsection{Influence of Loads on permeability}

Figure 6 shows the stress-strain curve and permeability-strain curve under the loads of $F=0 \mathrm{MPa}, F=5.28$ $\mathrm{MPa}, F=10 \mathrm{MPa}$ and failure $(F=12.4 \mathrm{MPa})$, which respectively corresponds to $\mathrm{A}, \mathrm{B}, \mathrm{C}, \mathrm{D}$ in stress-strain curve and $a, b, c, d$ in permeability-strain curve.

Due to mechanical transmission of the miniature loading device, there are two stress relaxation stages of

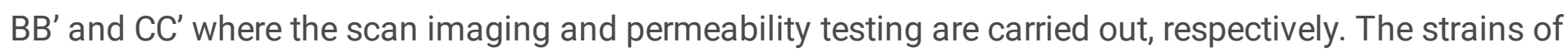
ceramic sample in these two stages are virtually remained unchanged, so they can't affect the experimental results and the height of the sample has little variation. During the experiment, $A$ point is the original state that has no loading and no permeability test, in this state, the $x$-ray imaging, permeability test and $x$-ray imaging are successively carried out in turn. $A B$ is first loading, $B^{\prime} C$ is second loading, $C^{\prime} D$ is last loading until the sample has been broken. The x-ray imaging, permeability test and $x$-ray imaging are successively carried out after each loading. For permeability-strain curve, as the strain increases, the permeability rate has a tendency to decrease for $a b$, and a slight rise for bc, the last a sharp rise for cd.

\subsection{Permeability variation mechanism}

Permeability rate is mainly determined by the inner pore structures of the sample. 3D rending of porous ceramic with pores and matrix (blue represents matrix, yellow is pore) has been built in Fig. 7, it has obvious changes for pores under different loading stages, while the pores of sample before and after permeability test have little noticeable change under the same load.

The visual cross-section views of a sample under different loads are exhibited in Fig. 8. For clarity, crosssection views are chosen from six different positions $\left(Z_{1}=0.64 \mathrm{~mm}, Z_{2}=1.31 \mathrm{~mm}, Z_{3}=1.97 \mathrm{~mm}, Z_{4}=\right.$ 
$2.64 \mathrm{~mm}, Z_{5}=2.97 \mathrm{~mm}$ and $Z_{6}=3.30 \mathrm{~mm}$ ) of sample, as clearly shown in Fig. 8(a). The porosities of these six positions under different loads were also illustrated Fig. 8(b), it is obvious that the porosities at different positions firstly decrease and then increase with the increasing of loads. Similarly, the slice images of these six positions can also reflect this tendency (see Fig. 8(c)). The black areas of these six cross-section positions after compression of $5 \mathrm{MPa}$ are smaller than those before loading, which indicates that pores inside the sample become smaller under this load. This trend corresponds to the permeability rate of sample after compression of $5 \mathrm{MPa}$. As the stress increases to $10 \mathrm{MPa}$, the porosity and the permeability rate have some increase. The stress continues to be increased, it is clear that the large cracks begin to appear for some cross-section views like $Z_{2}=1.311 \mathrm{~mm}, Z_{3}=1.971 \mathrm{~mm}, Z_{4}=2.636$ $\mathrm{mm}, Z_{5}=2.969 \mathrm{~mm}$ and $Z_{6}=3.301 \mathrm{~mm}$. These cracks provide the bigger channels for deionized water, which causes a sharp rise in the permeability rate of the sample. The cross-section views of each position before and after permeability have been displayed, respectively. Compared with cross-section views before permeability test, the pore structures of these cross-section views after permeability test have little noticeable change. It indicates that the water pressure $(0.08 \mathrm{MPa})$ inside sample almost doesn't impact on the pore structures at this stage.

Figure 9 displays the porosity distribution along the thickness (from $Z_{7}=0.256 \mathrm{~mm}$ to $Z_{8}=3.424 \mathrm{~mm}$ ) of porous ceramic with different loads. Note that it is verified that porosity of $\mathrm{C} / \mathrm{SiC}$ ceramic without any loads ranges from $10.6-15.1 \%$ along the thickness, namely uniformity $>95.4 \%$. In these curves, the porosity includes volume fraction of pores and cracks caused by loading. The changing trends of porosity of porous ceramic with different loads are consistent with those of permeability, which indicates cracks can also be the channels for deionized water in permeability tests. To investigate the variation of porosity of different cross-sections in porous ceramics under different loads, respectively, the dispersion degree of porosity of different cross-sections has been estimated according to the discrete variance formula accepted widely by researchers:

$$
\begin{gathered}
D(X)=\sum_{i=1}^{n} p_{i} \cdot\left(x_{i}-\mu\right)^{2} \\
\mu=E(X)
\end{gathered}
$$

where $D$ represents the dispersion of porosity of different cross-sections in the porous ceramic, $E$ is mathematical expectation of the porosity. The dispersion degree under loads of $0 \mathrm{MPa}, 5.28 \mathrm{MPa}$, and 10 $\mathrm{MPa}$ are $0.94,1.1,0.61$, separately. Note that dispersion degree after failure is 8.1 . It distinctly indicates pores along the thickness of porous ceramic without large cracks are uniform, which shows that the uniform distribution of pores can provide reasonable channels for deionized water in the transpiration cooling. 
The three-dimensional structure model of porous ceramic (the diameter of $4 \mathrm{~mm}$, and the height of 737 $\mu \mathrm{m})$ has been restructured with Avizo software in order to see the pore structures clearly, pores have been uniformly distributed in the porous ceramic (see Fig. 10(a)). After maximum loading, the pore structures including pores and cracks are displayed in Fig. 10(b), blue region represents pores and red part shows cracks. Compared to porous ceramic before loading in Fig. 10(a), it is clearly seen that large cracks have randomly appeared in the porous ceramic, and these cracks can also be the channels for deionized water in the experiment, so the permeability has a sharp increase in cd in Fig. 6. The porosity formed from cracks is very non uniform along the thickness direction of porous ceramic (see Fig. 9). Therefore, these pore channels of porous ceramic after achieving maximum loading cannot control accurately and uniformly water flow.

\section{Conclusions}

In order to quantitatively elucidate the permeability evolution behaviors of a $\mathrm{C} / \mathrm{SiC}$ porous ceramic, an in situ compression-permeation testing rig was designed with high-resolution synchrotron radiation X-ray imaging beam line BL13W1 at the SSRF. Through interrupted pressure process, the following conclusions can be drawn:

1. The visualization for permeability mechanism of porous ceramic can be displayed by threedimensional streamlines, which can indirectly reflect the porosity and the size distribution of open pores of the porous ceramic.

2. The porosity along the thickness of ceramic under different loads can be obtained based on in-situ synchrotron X-ray tomography investigation. It's worth noting that the uniform distribution of porosity along the thickness of $\mathrm{C} / \mathrm{SiC}$ porous ceramic sample without loads has been verified.

3. The permeability evolution rule of porous ceramic with water is obtained under different loads. As the load increases, the permeability rate firstly decreases and then conversely becomes larger. This phenomenon is determined by the evolution of pore channels inside the porous ceramic.

\section{Declarations}

\section{Acknowledgement}

This work was supported by the National Natural Science Foundation of China (11772042 and U2032121).

\section{References}

1. Camillo GP, Wagner A, Dittert C, Benjamin L, Wartemann V, Neumann J, Hink R (2020) Experimental investigation of the effect of transpiration cooling on second mode instabilities in a hypersonic boundary layer. Exp Fluids 61:162 
2. Ma C, Ma Z, Gao LH, Liu YB, Wang JW, Song MY, Wang FC, Ishida H (2018) Laser ablation behavior of nano-copper particle-filled phenolic matrix nanocomposite coatings. Compos Part B-Eng 155:6268

3. Li JS, Yu QP, Li D, Zeng L, Gao ST (2021) Formation of hierarchical Si3N4 foams by protein-based gelcasting and chemical vapor infiltration. J Adv Ceram 10(1):187-193

4. Hayashi T, Wakayama S (2009) Thermal fatigue behavior of 3D-woven SiC/SiC composite with porous matrix for transpiration cooling passages. Adv Compos Mater 18:61-75

5. Tao S, Xu YD, Gu JQ, Abadikhah H, Wang JW, Xu X (2018) Preparation of high-efficiency ceramic planar membrane and its application for water desalination. J Adv Ceram 7(2):117-123

6. Zhang B, Huang HM, Lu XL, Peng JL (2020) Experimental investigation on transpiration cooling for porous ceramic with liquid water. Acta Astronaut 167:117-121

7. Zhang B, Huang HM, Huang J, Chen JL (2020) An experimental investigation on performance of transpiration cooling with liquid water through C/SiC porous ceramic. Appl Therm Eng 178:115526

8. Li DX, Jiang P, Gao RH, Sun F, Jin XC, Fan XL (2021) Experimental and numerical investigation on the thermal and mechanical behaviours of thermal barrier coatings exposed to CMAS corrosion. $J$ Adv Ceram 10(3):551-564

9. Wu ZJ, Wang Z, Shi GD, Sheng J (2011) Effect of surface oxidation on thermal shock resistance of the ZrB2-SiC-ZrC ceramic. Compos Sci Technol 71:1501-1506

10. Liu S, Zhang BM (2010) Experimental study on a transpiration cooling thermal protection system. Sci China Technol Sc 53:2765-2771

11. Li DY, Wang RZ, Wang XR, Li WG (2020) Simulation of the thermal shock cracking behaviors of ceramics under water quenching for 3-dimension conditions. Eur J Mech A-Solid 84:104080

12. Zhang $Y X$, Wang KF, Wang BL, Zhang $C$ (2020) Thermal shock resistance of porous ceramic foams with temperature-dependent material properties. Ceram Int 46(2):1503-1511

13. Najmi H, Gascoin N, Chetehouna K, El-Tabach E, Akridiss S (2019) Transient and spatial evolution of clogging of porous material by filtrating particles. Ind Eng Chem Res 58:12261-12271

14. Ali MA, Umer R, Khan KA, Cantwell WJ (2019) Application of X-ray computed tomography for the virtual permeability prediction of fiber reinforcements for liquid composite molding processes: $A$ review. Compos Sci Technol 184:107828

15. Yang L, Chen W, Chyu MK (2018) A convolution modeling method for pore plugging impact on transpiration cooling configurations perforated by straight holes. Int J Heat Mass Tran 126:10571066

16. Ying Q, Zhang HB, Zhao J, Wu WB, Gu B, Feng XQ (2021) Influence of considering the sorption effect in the betti-maxwell reciprocal theorem on gas transport capacity in unconventional reservoirs. Transport Porous Med 137:451-469

17. Dou FK, Wang JG, Leung CF, Ma ZG (2021) The alterations of critical pore water pressure and microcracking morphology with near-wellbore fractures in hydraulic fracturing of shale reservoirs. Eng 
Fract Mech 242:107481

18. Chen BW, Ding Q, Ni DW, Wang HD, Ding YS, Zhang XY, Dong SM (2020) Microstructure and mechanical properties of 3D C-f/SiBCN composites fabricated by polymer infiltration and pyrolysis. $J$ Adv Ceram 10(1):28-38

19. Tseng SC, Chao CK, Zhang WX, Fan XL (2020) Microcrack propagation induced by dynamic infiltration of calcium-magnesium-alumino-silicate in columnar structures for thermal barrier coatings. J Chin Inst Eng 44:11-21

20. Li XQ, Yao DX, Zuo KH, Xia YF, Yin JW, Liang HQ, Zeng YP (2020) Microstructure and permeability of porous YSZ ceramics fabricated by freeze casting of oil-in-water suspension. J Eur Ceram Soc 40:5845-5851

21. Smirnov NN, Legros JC, Nikitin VF, Istasse E, Schramm L, Wassmuth F (2003) D'Arcy Hart, Filtration in artificial porous media and natural sands under microgravity conditions. Microgravity Sci Technol $14: 3-28$

22. Zhang T, He X, Liu Y, Zhao YX, Yang K, Yu X, Experimental study on permeability response in fractured rock to the effect of hydro-mechanical coupling, fracture geometry, and component content, Nat. Hazards, (2020)

23. Zhao Y, Wang CL, Bi J (2020) Analysis of fractured rock permeability evolution under unloading conditions by the model of elastoplastic contact between rough surfaces. Rock Mech Rock Eng 53:5795- 5808

24. Zheng J, Wang XH, Lu Q, Sun HY, Guo JC (2020) A new determination method for the permeability tensor of fractured rock masses. J Hydrol 585:124811

25. Quan ZZ, Larimore Z, Qin XH, Yu JY, Mirotznik M, Byun JH, Oh Y, Chou TW (2016) Microstructural characterization of additively manufactured multi-directional preforms and composites via X-ray micro-computed tomography. Compos Sci Technol 131:48-60

26. Bai TT, Dong BB, Xiao MJ, Liu H, Wang N, Wang YM, Wang C, Liu CT, Cao W, Zhang JX, Ma Y, Guo ZH (2018) Polystyrene foam with high cell density and small cell size by compression-injection molding and core back foaming technique: evolution of cells in cavity. Macromol Mater Eng 303:1800110

27. Ren CX, Hu ZF, Yao C, Mo F (2019) Experimental study on the quasi-static compression behavior of multilayer aluminum foam sandwich structure. J Alloy Compd 810:151860

28. Wei ZZ, Lin JY, Wang XL, Huang LQ, Yu JY, Li FX (2015) In situ polymerization of biodegradable poly(butylene-co-succinate terephthlate) nanocomposites and their real-time tracking of microstructure. Compos Sci Technol 117:121-129

29. Zhang B, Huang HM, Lu XL (2019) Fabrication and properties of C/SiC porous ceramics by grindingmould pressing-sintering process. J Eur Ceram Soc 39:1775-1780

30. Chen ZH, Sun FF, Zou Y, Song F, Zhang S, Jiang Z, Wang Y, Tai RZ (2018) Design of wide-range energy material beamline at the Shanghai Synchrotron Radiation Facility. Nucl Sci Tech 29:26

31. Xiao TQ, Xie HL, Deng B, Du GH, Chen RC (2014) Progress of X-ray imaging methodology and its applications at Shanghai Synchrtron Radiation Facility. Acta Optica Sin 34:0100001 
32. Xie HL, Luo HX, Du GH, Zhao CQ, Xu WD, Zhou GZ, Chen RC, Xiao TQ (2019) High-efficiency fast Xray imaging detector development at SSRF. J Synchrotron Radiat 26:1631-1637

33. Cao XF, Huang ZX, He CW, Wu WW, Xi L, Li Y, Fang DN (2021) In-situ synchrotron X-ray tomography investigation of the imperfect smooth-shell cylinder structure. Compos Struct 267:113926

34. Hu YN, Wu SC, Chen L (2019) Review on failure behaviors of fusion welded high-strength Al alloys due to fine equiaxed zone. Eng Fract Mech 208:45-71

35. Hu XF, Wang LB, Xu F, Xiao TQ, Zhang Z (2014) In situ observation of fractures in short carbon fiber/epoxy composites. Carbon 67:368-376

36. Wu SC, Xiao TQ, Withers PJ (2017) The imaging of failure in structural materials by synchrotron radiation X-ray micro-tomography. Eng Fract Mech 182:127-156

37. Li YG, Duan TC, Yao GB, Tang YJ, Miao WJ, Wang ZB (2019) Structural evolution of stretch deformed HDPE/RGO nanocomposites: an in-situ synchrotron SAXS and WAXD study. Compos Sci Technol 183:107798

38. Xie HL, Deng B, Du GH, Fu YN, Guo H, Xue YL, Peng GY, Tao F, Zhang L, Xiao TQ (2020) Methodology development and application of X-ray imaging beamline at SSRF. Nucl Sci Tech 31:102

39. Goncharov AF, Kong LP, Mao HK (2019) High-pressure integrated synchrotron infrared spectroscopy system at the Shanghai Synchrotron Radiation Facility. Rev Sci Instrum 90:093905

40. Zhang B, Huang J, Li WJ, Huang HM, Zhao HY, Peng JL (2020) Synthesis and characterization of light-weight porous ceramics used in the transpiration cooling. Acta Astronaut 177:438-445

41. Wang ZY, Wu SC, Kang GZ, Li H, Wu ZK, Fu YN (2021) P.J. Withers. In-situ synchrotron X-ray tomography investigation on damage mechanism of an extruded magnesium alloy in uniaxial lowcycle fatigue with ratchetting. Acta Mater 211:116881

42. Hu YN, Wu SC, Withers PJ, Zhang J, Bao HYX, Fu YN, Kang GZ (2020) The effect of manufacturing defects on the fatigue life of selective laser melted Ti-6Al-4V structures. Mater Des 192:108708

43. Xie C, Wu SC, Yu YK, Zhang HO, Hu YN, Zhang MB, Wang GL (2021) Defect-correlated fatigue resistance of additively manufactured Al-Mg4.5Mn alloy with in situ micro-rolling. J Mater Process Technol 291:117039

44. Ai SG, Song WL, Chen YF (2021) Stress field and damage evolution in C/SiC woven composites: Image-based finite element analysis and in situ X-ray computed tomography tests. J Eur Ceram Soc 41:2323-2334

45. Wijaya W, Ali MA, Umer R, Khan KA, Kelly PA, Bickerton S, An automatic methodology to CT-scans of 2D woven textile fabrics to structured finite element and voxel meshes, Compos. Part A-Appl. S., 129 (2019) 105561

46. Gunduz DC, Schierholz R, Yu SC, Tempel H, Kungl H, Eichel RA (2020) Combined quantitative microscopy on the microstructure and phase evolution in Li1.3Al0.3Ti1.7(PO4)(3) ceramics. J Adv Ceram 9(2):149-161 


\section{Figures}

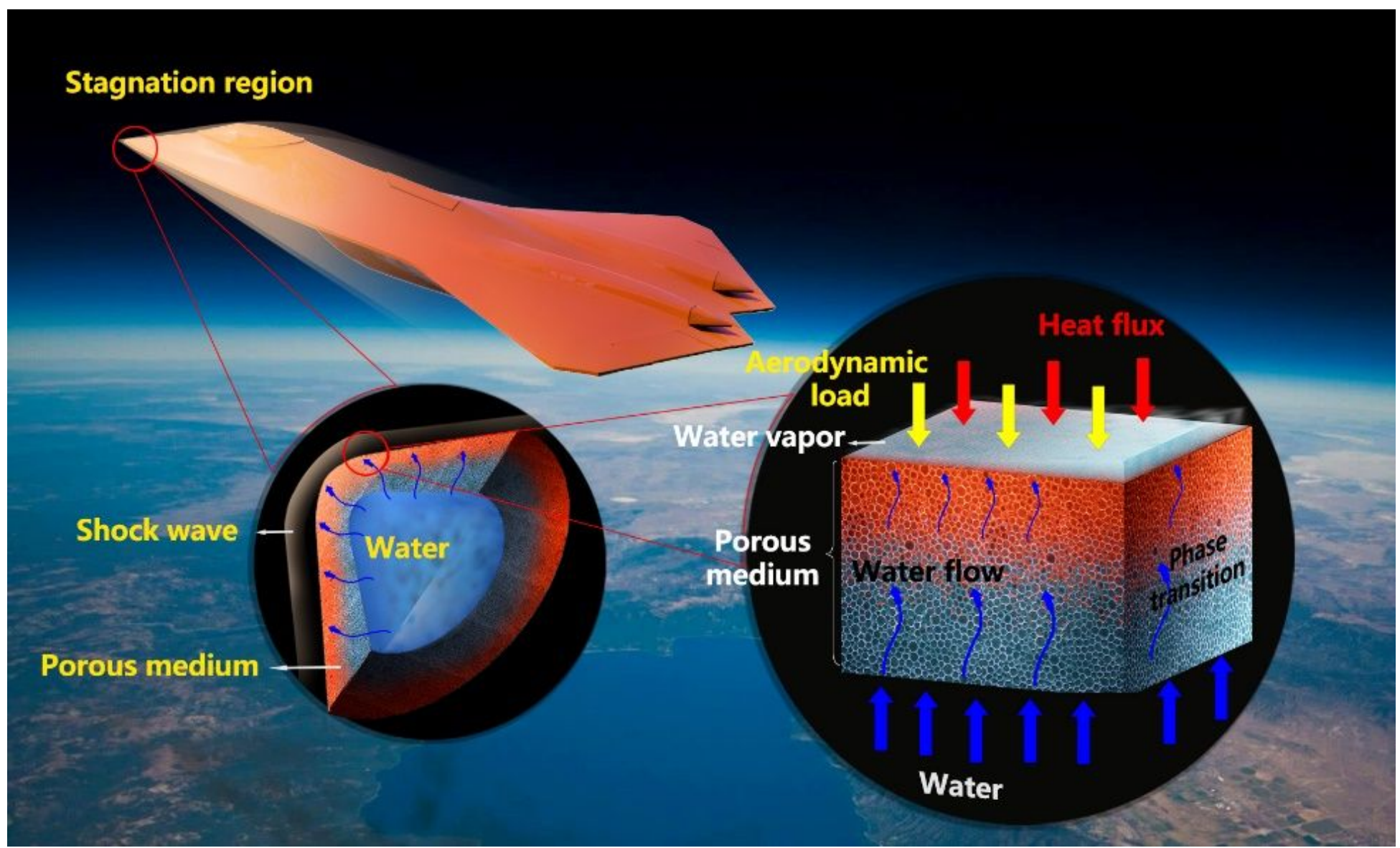

\section{Figure 1}

The schematics of future hypersonic vehicles where external surfaces of the stagnation region show excellent heat exchange.
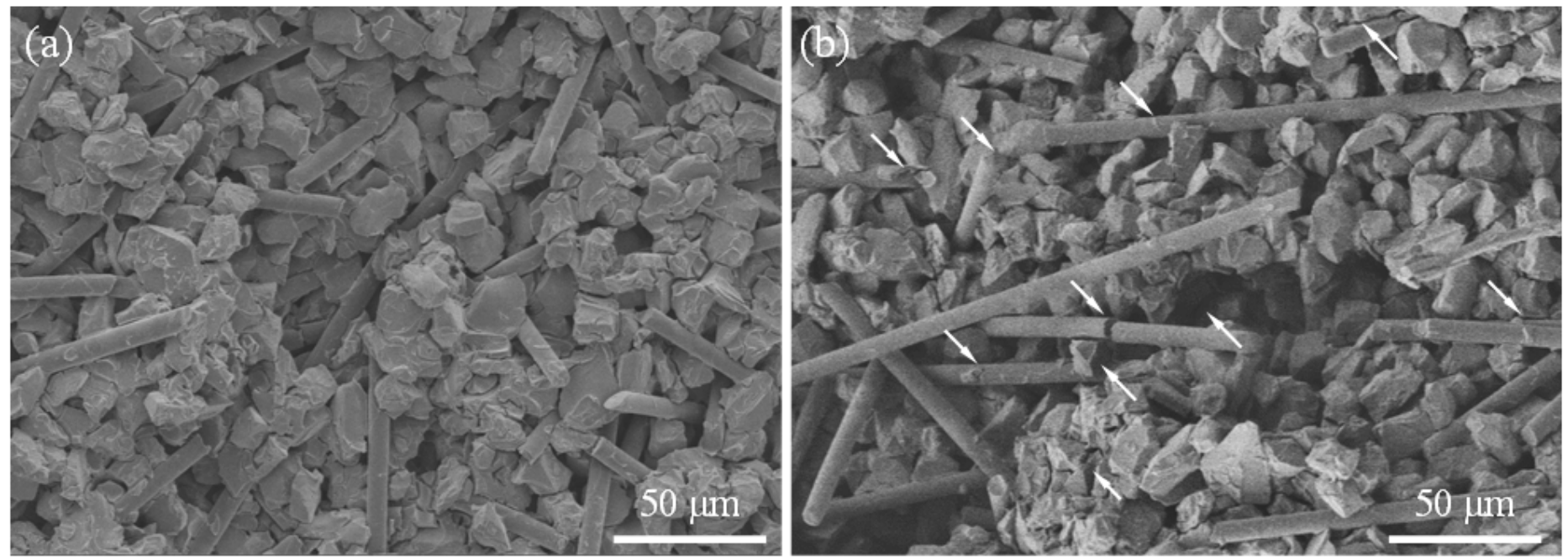

Figure 2 
The fractured $\mathrm{C} / \mathrm{SiC}$ porous ceramic showing distinct failure features of fibers and particles in (a) static tensile sample; (b) compressed sample.

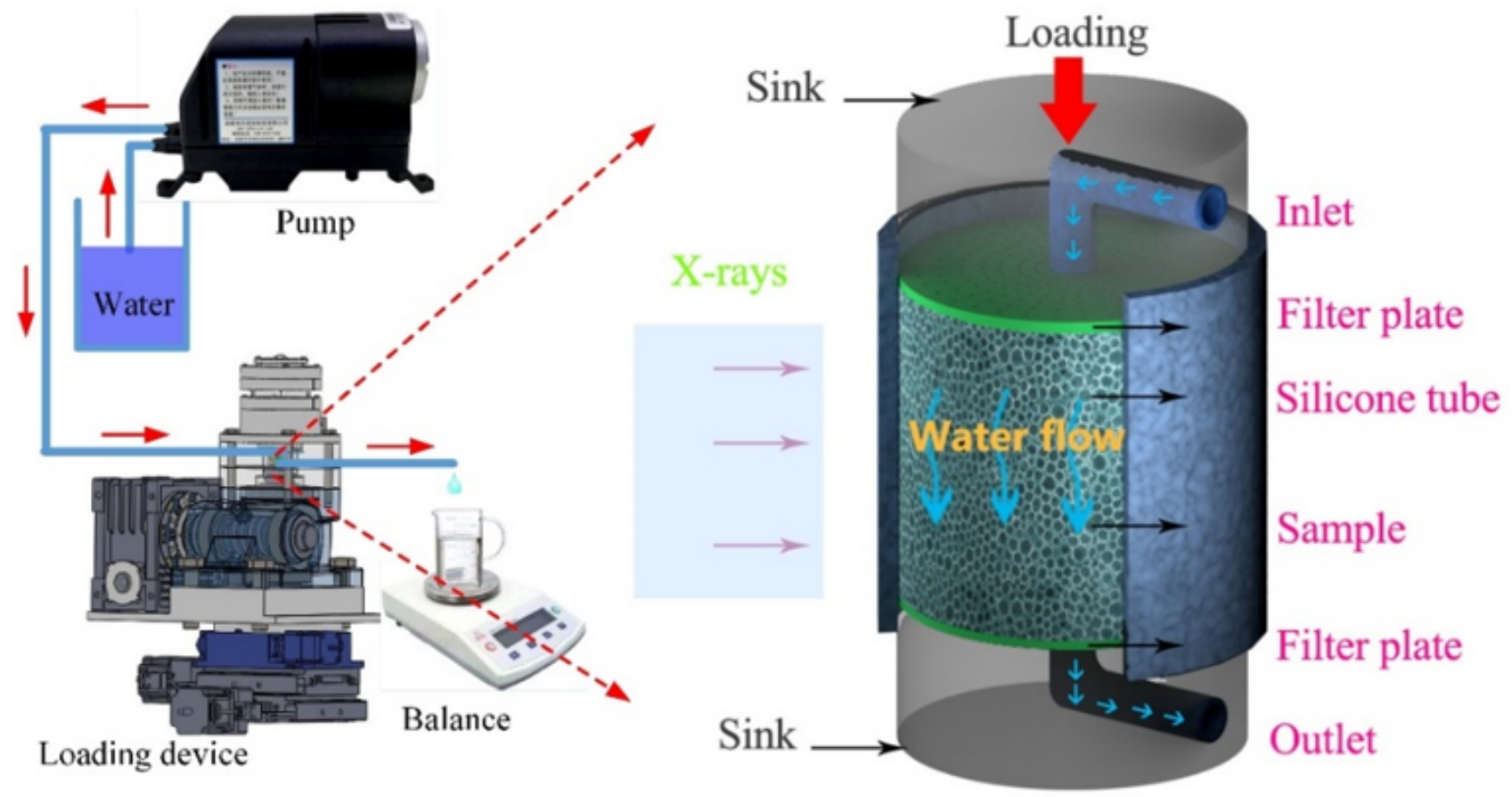

\section{Figure 3}

The schematics of in-situ miniature permeability compression testing rig and thorough experimental process at the BL13W1 of SSRF.
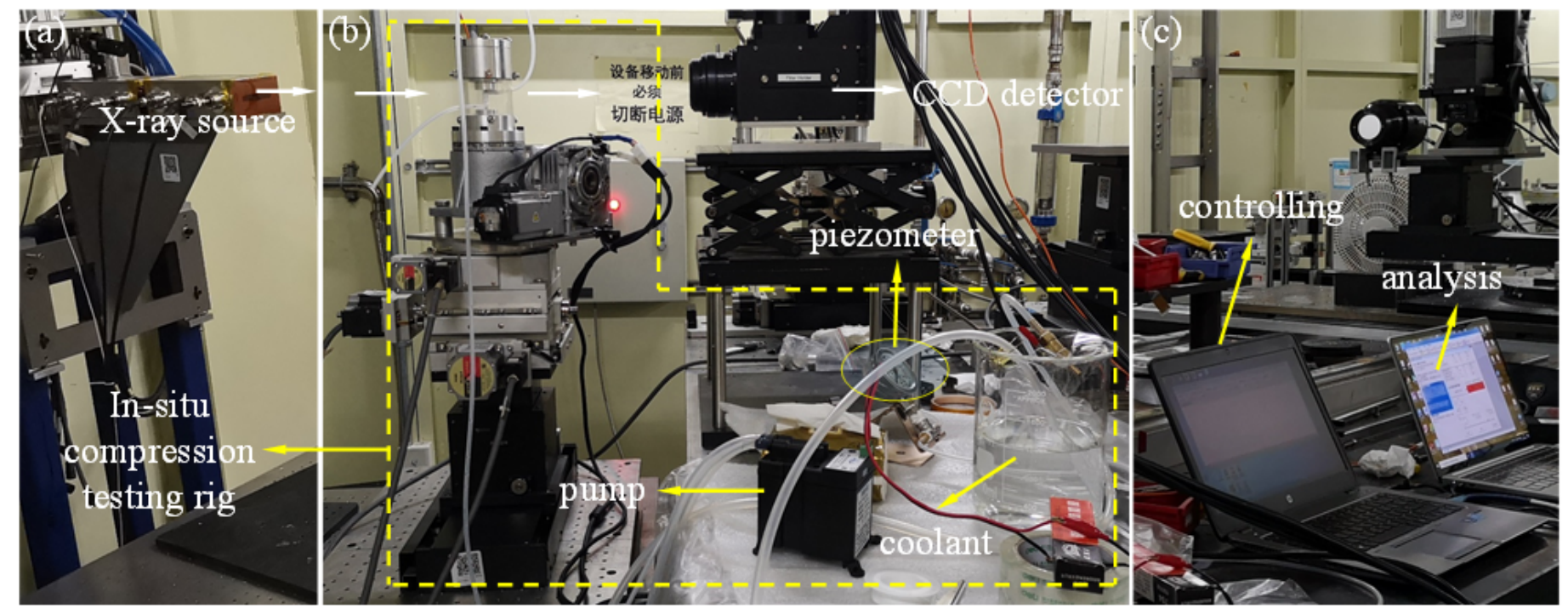

Figure 4

Field experimental pictures with X-ray source, in-situ compression device, CCD detector, inlet / outlet water devices and user controling. 


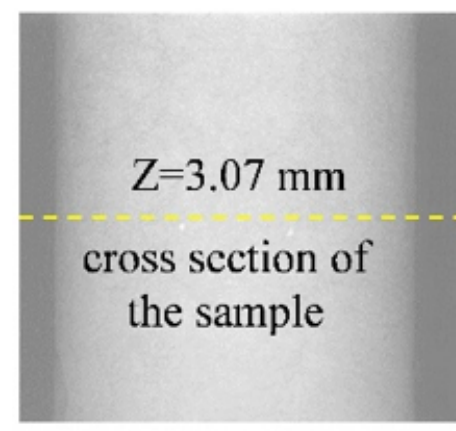

(a) raw image

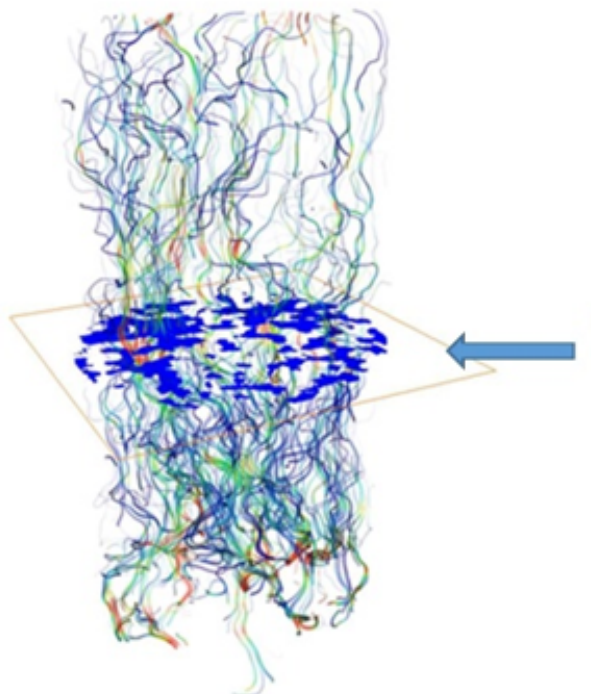

(f) streamlines

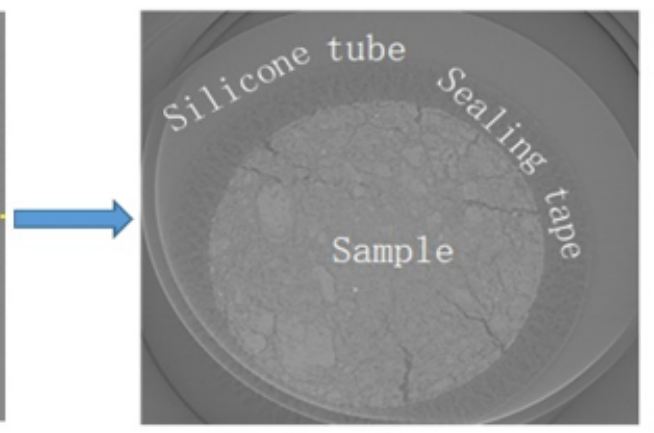

(b) slice image

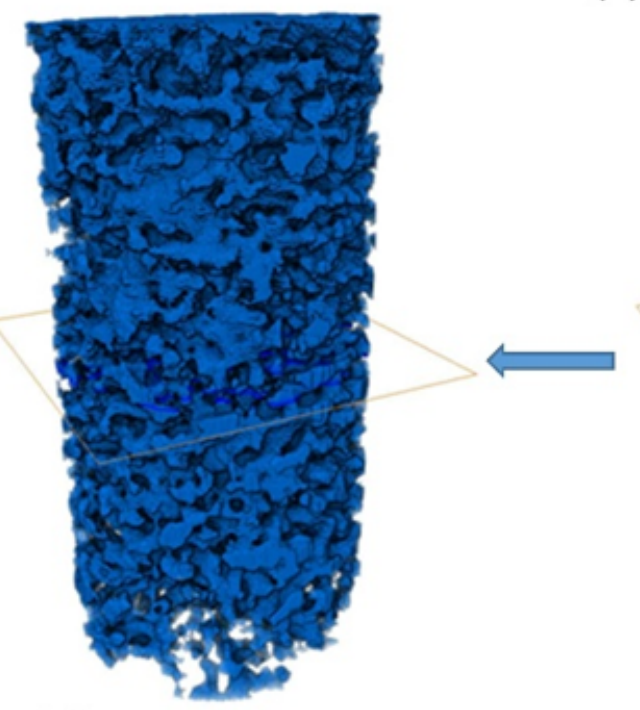

(e) pore structure
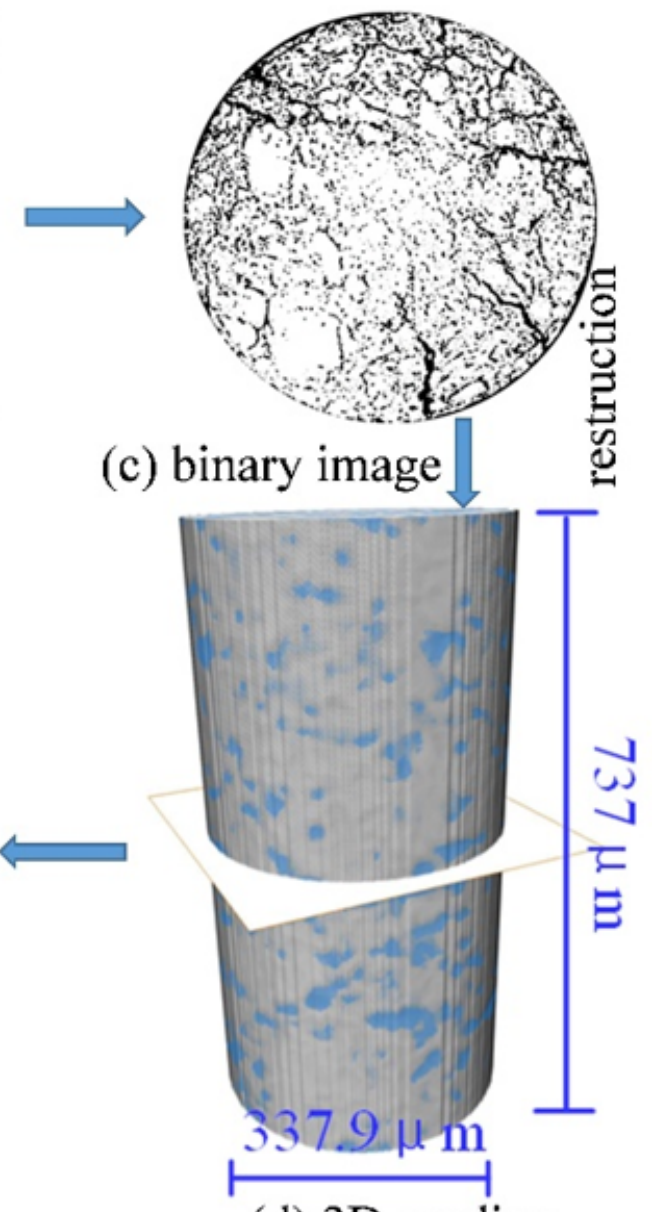

(d) $3 \mathrm{D}$ rending

\section{Figure 5}

Schematic permeability mechanism of $\mathrm{C} / \mathrm{SiC}$ porous ceramic through synchrotron $\mathrm{X}$-ray tomography and data construction. 


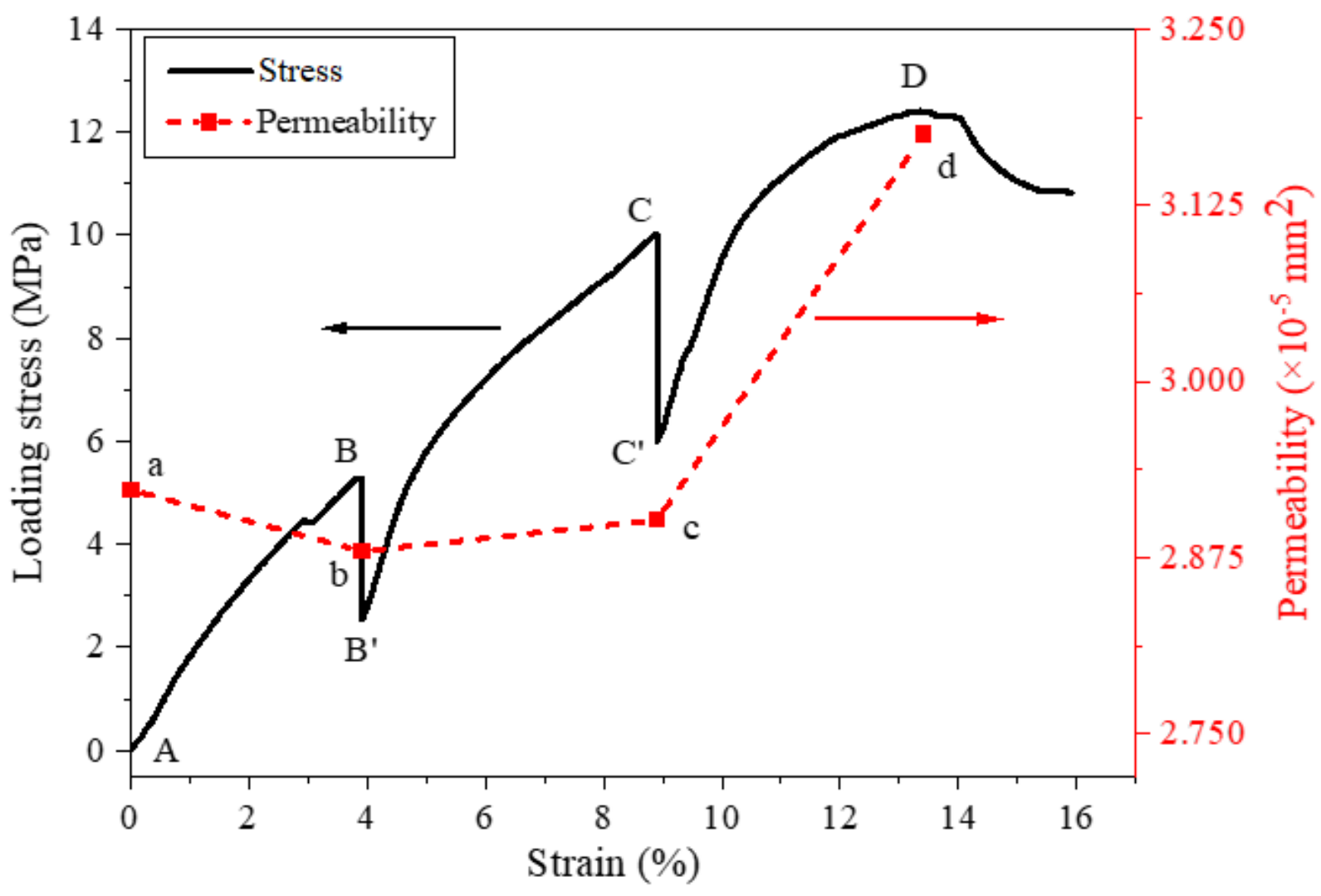

Figure 6

Permeability behavior of $\mathrm{C} / \mathrm{SiC}$ porous ceramics subjected to interrupted negative loading with synchrotron X-ray tomography. 


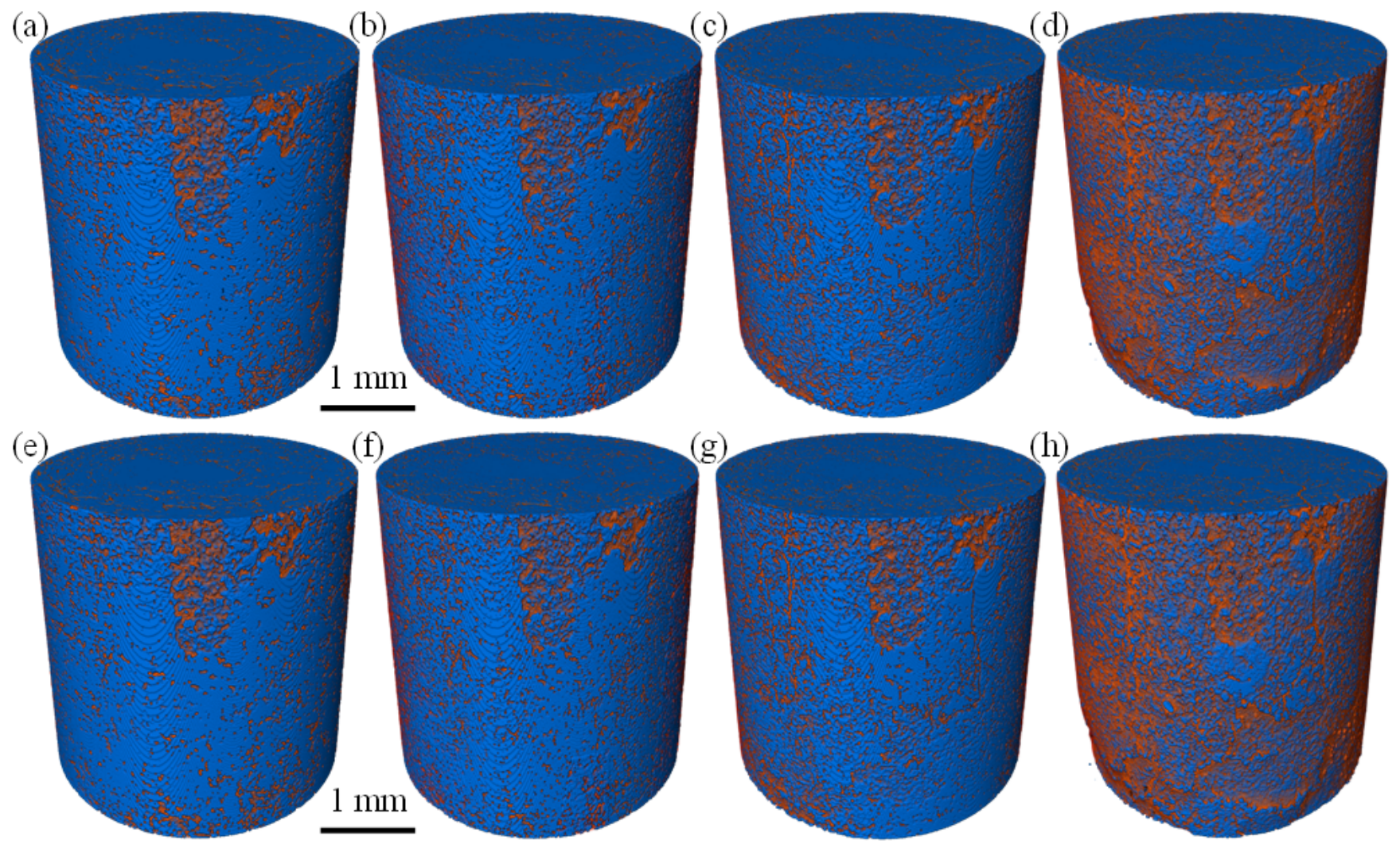

Figure 7

3D rending of permeability under different loading stages (a)-(d) before permeability and (e)-(h) after permeability, and (a) and (e) under $\mathrm{F}=0 \mathrm{MPa}$, (b) and (f) under $\mathrm{F}=5.28 \mathrm{MPa}$, (c) and (g) under $\mathrm{F}=10 \mathrm{MPa}$, (d) and (h) under $\mathrm{F}=12.4 \mathrm{MPa}$. 

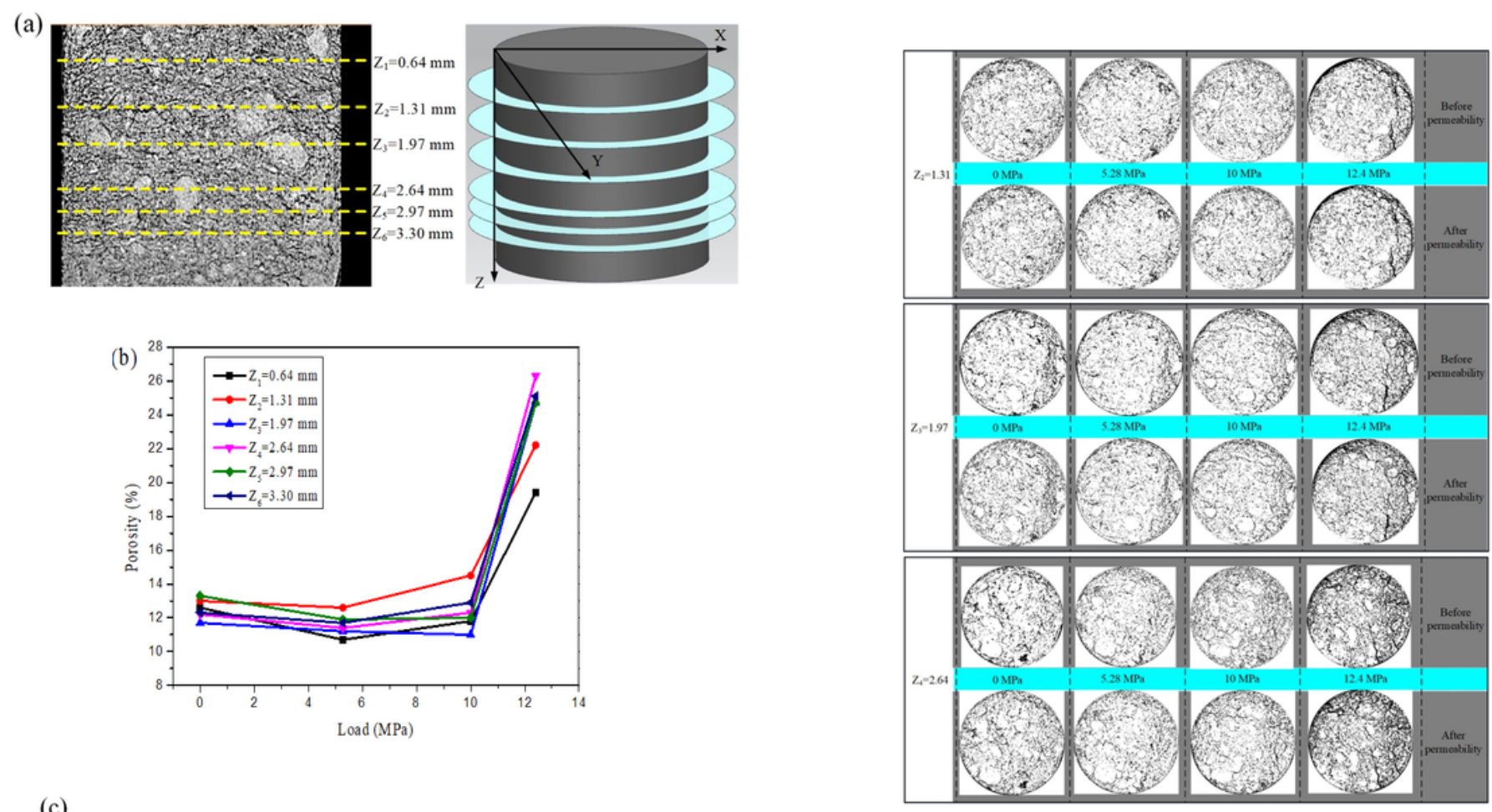

(c)
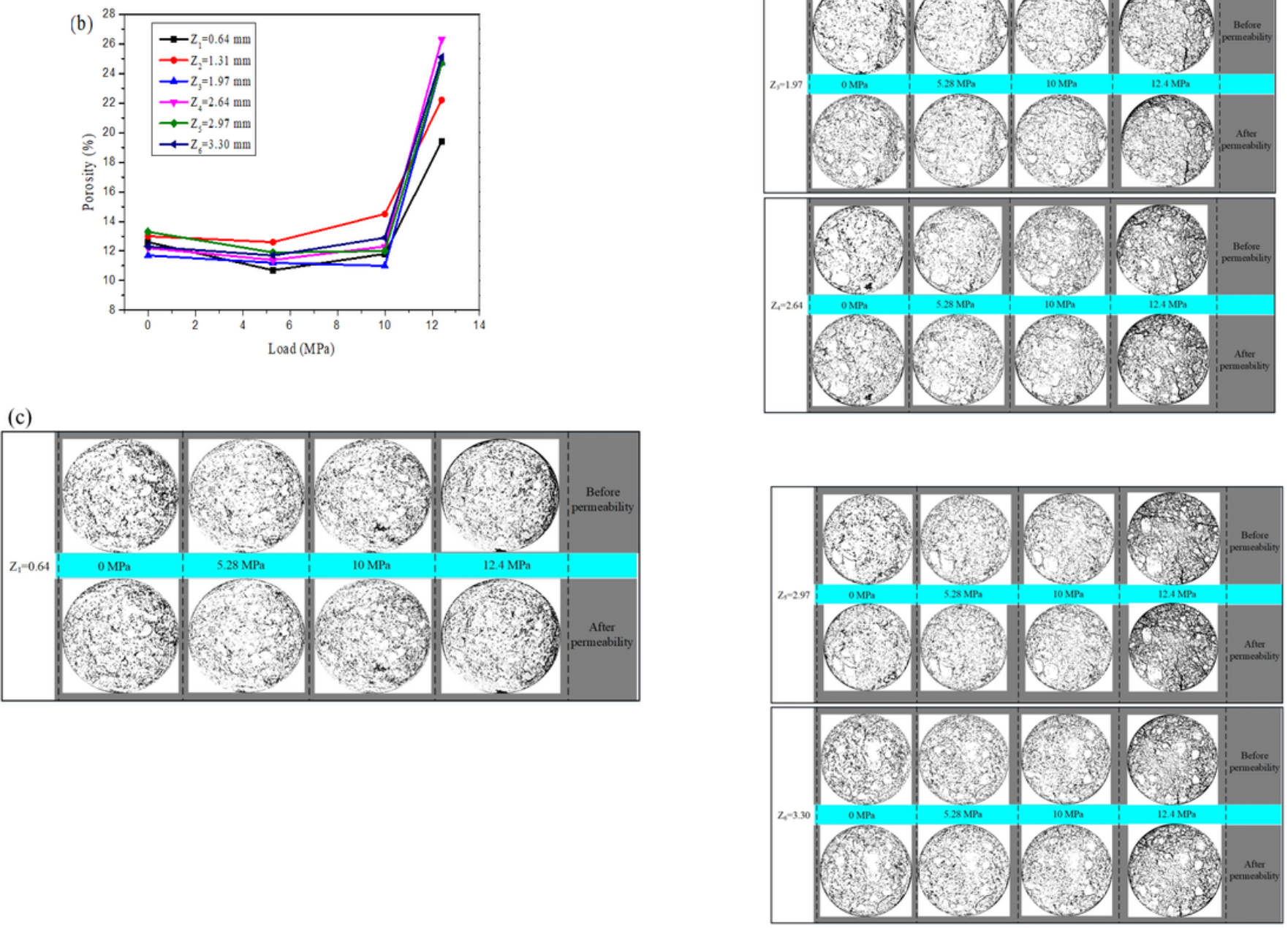

Figure 8

Effect of different loading stages on the porosities across different cross-sections: (a) cross-sections extraction; (b) curves; (c) slice images 


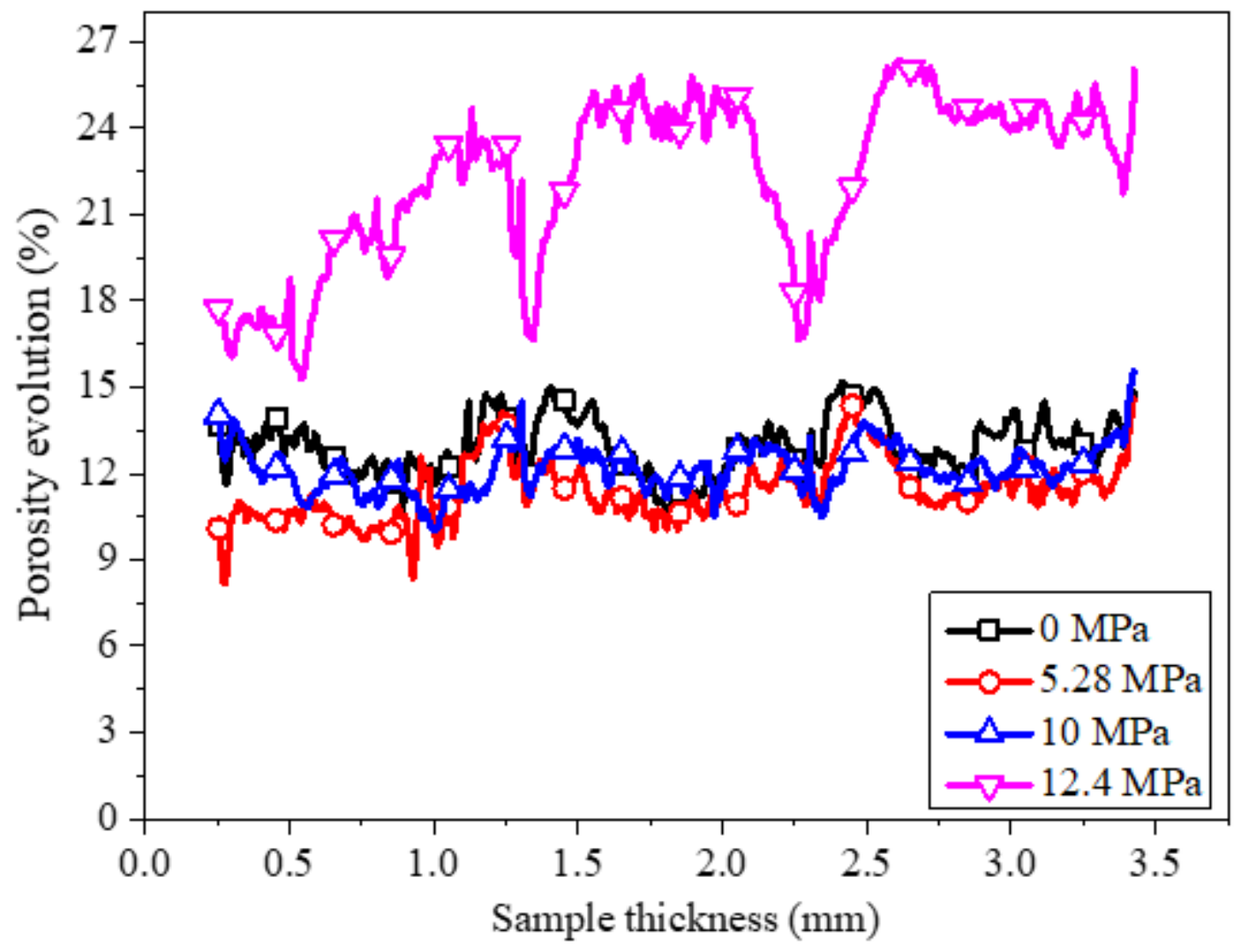

Figure 9

Measured porosity distribution curves along the thickness direction of $\mathrm{C} / \mathrm{SiC}$ porous ceramic under four loading levels.

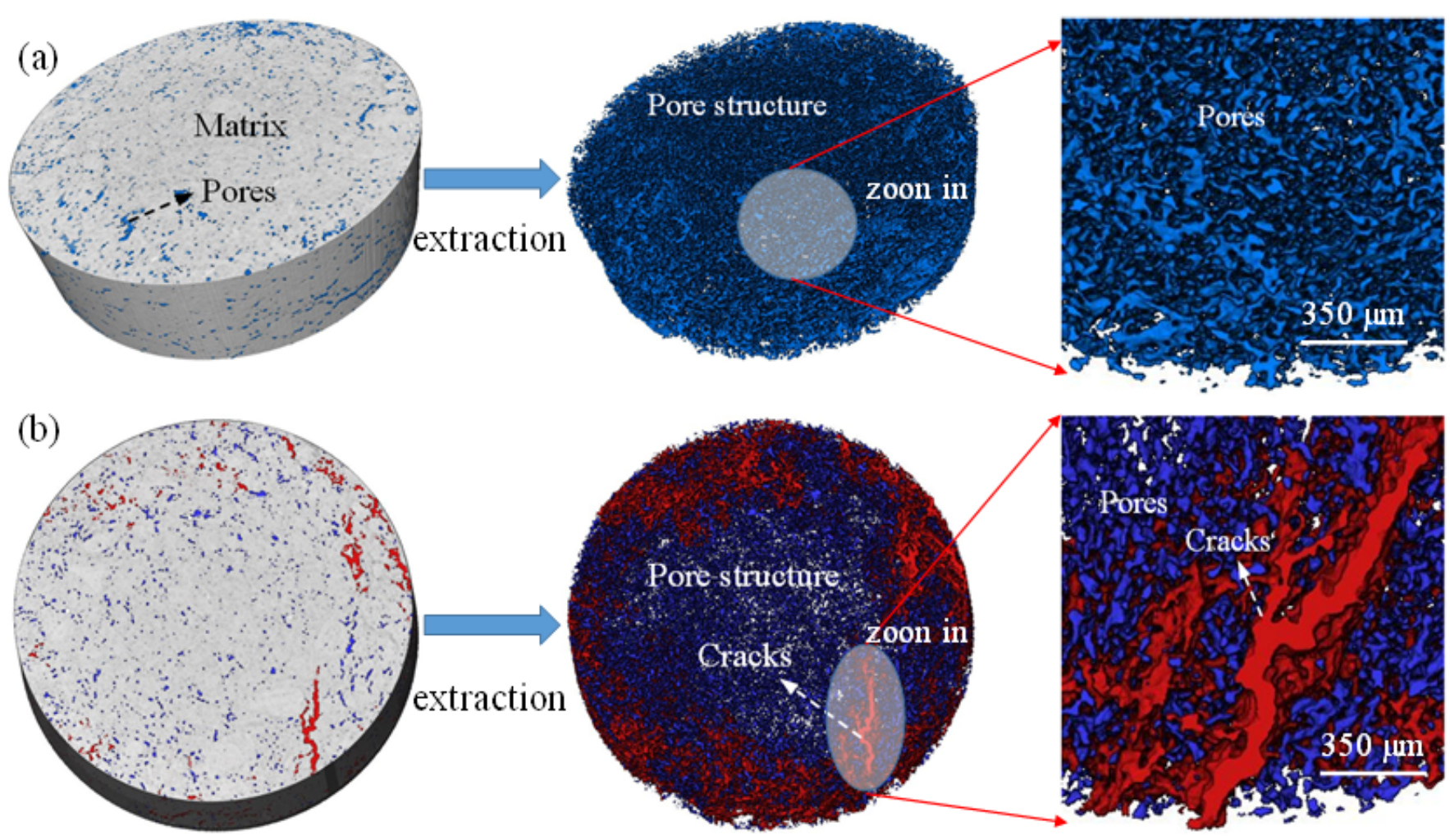


Figure 10

Microstructural evolution features of $\mathrm{C} / \mathrm{SiC}$ porous ceramic using high-resolution X-ray tomography: (a) without load; (b) failure after loading.

\section{Supplementary Files}

This is a list of supplementary files associated with this preprint. Click to download.

- Streamlines000000000030.gif 